\title{
Contraceptive Choices Pre and Post Pregnancy in Adolescence
}

\author{
L. Correia MD*, I. Martins MD, N. Oliveira MD, I. Antunes MD, F. Palma MD, M.J. Alves MD \\ Adolescence Unit of Maternity Dr. Alfredo da Costa - Centro Hospitalar de Lisboa Central, Lisbon, Portugal
}

\begin{abstract}
A B S T R A C T
Study Objective: The main aim of this study is to evaluate the impact of adolescent pregnancy in the future contraceptive choices. A secondary aim is to verify whether these choices differ from those made after an abortion.

Design: Retrospective study.

Setting: Adolescent Unit of a tertiary care center.

Participants: 212 pregnant teenagers.

Interventions: Medical records review.

Main Outcome Measures: Intended pregnancy rate and contraceptive methods used before and after pregnancy. For contraceptive choices after pregnancy we considered: Group 1 - teenagers who continued their pregnancy to delivery $(\mathrm{n}=106)$ and Group 2 - the same number of adolescents who chose to terminate their pregnancy.

Results: The intended pregnancy rate was $14.2 \%$. Prior to a pregnancy continued to delivery, the most widely used contraceptive method was the male condom (50.9\%), followed by oral combined contraceptives (28.3\%); $18.9 \%$ of adolescents were not using any contraceptive method. After pregnancy, contraceptive implant was chosen by $70.8 \%$ of subjects $(P<.001)$ and the oral combined contraceptives remained the second most frequent option (17.9\%, $P=.058$ ). Comparing these results with Group 2 , we found that the outcome of the pregnancy was the main factor in the choices that were made. Thus, after a pregnancy continued to delivery, adolescents prefer the use of LARC [78.4\% vs 40.5\%, OR: 5,958 - 95\% (2.914-12.181), $P<.001$ )], especially contraceptive implants [70.8\% vs 38.7\%, OR: 4.371 - 95\% (2.2248.591), $P<.001$ ], to oral combined contraceptives [17.9\% vs 57.5\%, OR: $0.118-95 \%$ CI $(0.054-0.258), P<.001$ ].
\end{abstract} Conclusion: Adolescent pregnancy and its outcome constitute a factor of change in future contraceptive choice. Key Words: Contraception, Adolescence, Pregnancy

\section{Introduction}

The decision on how, when, and which contraceptive method one should use is a complex issue for teenagers. Even though they increasingly use contraceptive methods in general and especially birth control at first intercourse, consistent use remains a challenge in this age group, ${ }^{1}$ thus turning teenagers into a major risk group for unplanned pregnancy.

Most teenagers do not use the health care services available to them for contraceptive advice, friends and partners being the main sources of information. ${ }^{2}$ Half of teenage pregnancies occur in the first 6 months after the onset of sexual activity ${ }^{3}$ and about a fifth during the first month. ${ }^{1}$

The choice of contraceptive methods by adolescents may be influenced by a wide range of factors, among which are: prior knowledge of the method, its cost, side effect profile, efficacy, discretion, invasiveness, easy access and use and the possibility of forgetting to take it. ${ }^{4,5}$

Few studies evaluate the use of postpartum contraceptives choices in adolescence, but they are unanimous in the usefulness of long-active reversible contraceptives (LARC) for preventing future unplanned pregnancies. ${ }^{6-9}$

\footnotetext{
The authors indicate no conflicts of interest.

* Address correspondence to: L. Correia, MD, Praça das Flores Nㅜ $32^{\circ}$ Dto 2625-419 Forte da Casa, Portugal; Phone: 0351934236134

E-mail address: luciaaccorreia@gmail.com (L. Correia).
}

The main aim of this study is to evaluate the impact of teenager's pregnancy on future contraceptive choice and a secondary aim is to evaluate whether there are differences between the choices made by adolescents who continued with their pregnancy versus those who opted for induced abortion. Based on the reality of our Adolescent unit, we hypothesized that the pregnancy determines deep changes in the contraceptive choices, making the use of LARC preferable in teenagers that continued pregnancy till delivery.

\section{Materials and Methods}

This retrospective study included pregnant teenagers followed in the Adolescent Unit of the Maternity Dr. Alfredo da Costa, between 2007 and 2010.

In this unit is a multidisciplinary team composed of gynecologist/obstetrician doctors, nurses, social workers, psychologists, and nutritionists. The surveillance of pregnant teenagers, the monitoring of cases that chose voluntary termination of pregnancy, and the contraceptive counseling is always carried out by the same health professionals, during pregnancy or termination of pregnancy and after delivery or abortion. The different methods are presented and provided, leaving the decision to the teenager.

During the study, we analyzed the medical records of all the teenagers followed at the unit for data collection. Those who had no information on several variables: demographic 
characteristics (age, race, parity, education level, and profession), pregnancy planning and contraceptive methods used before and after pregnancy, were excluded. A final sample of 106 teenagers who decided to continue the pregnancy was obtained.

After comparing pre- and postpregnancy contraceptive choices made by adolescents who chose to carry their pregnancies until delivery (Part I), the authors compared the contraceptive methods chosen by those teenagers, Group 1, with those chosen by teenagers who opted for abortion, Group 2 (Part II).

As the number of teenagers who opt for the termination of pregnancy exceeds those who opt for continuing the pregnancy, for Group 2 we randomly selected an equal number of adolescents $(n=106)$ who chose to terminate the pregnancy at the same period of time. We considered contraceptive choices after pregnancy to be those which were made after the end of breastfeeding, and we considered contraceptive choices made after the termination of pregnancy those made after the first follow-up consultation (1 month after the procedure).

Long-active reversible contraceptives are those which require less than 1 administration per month or per cycle and include the contraceptive implant, intrauterine devices and 3-month injectable progestin.

In Portugal, compulsory schooling starts at the age of 6 ( $1^{\text {st }}$ grade) and it is continues till the $12^{\text {th }}$ grade, each year of age corresponding to a school year. School failure exists whenever there isn't a correct concordance between the age and the corresponding school year.

We used the Statistical Package for Social Sciences (SPSS) version 16.0 (SPSS Inc, Chicago, IL) for statistical analysis. For the comparison of paired samples we used the Wilcoxon test and for the comparison of independent samples we used the Student t-test (continuous variables) and the chisquare and Fisher exact test (categorical variables). A multivariate analysis was done to control demographic differences between 2 independent samples. For a significance level $\alpha=0.05$, we considered the existence of statistical significance when $P<.05$.

\section{Results}

Part I - Contraceptive Choices Pre and Post Pregnancy Carried Until Delivery

\section{Sample Description}

We included 106 pregnant adolescents, aged 13 to 18 (average age: $16 \pm 1 \mathrm{y}$ ). The adolescents were mostly single (92\%), nulliparous (98\%), Caucasian $(\mathrm{n}=70,66 \%)$ and students $(n=65,61 \%)$, Table 1 .

\section{Pregnancy Planning}

The intended pregnancy rate was $14 \%$, with adolescents aged 15 or younger representing one third of the cases. When comparing adolescents with a intended pregnancy with those with an unintended pregnancy, there were no statistically significant differences regarding age and race. The teenagers who planned their pregnancy are more frequently married or live with a partner $(53 \%)$ and had a
Table 1

Demographic Characteristics from Adolescents who Carried Pregnancy Until Delivery

\begin{tabular}{lc}
\hline & $\mathrm{N}(\%)$ \\
\hline Age & \\
$\leq 15 \mathrm{y}$ & $31(29.2)$ \\
$>15 \mathrm{y}$ & $75(70.8)$ \\
Race & \\
$\quad$ Caucasian & $70(66)$ \\
Non-Caucasian & $36(34)$ \\
Parity & \\
Nulliparous & $104(98.1)$ \\
Multiparous & $2(1.9)$ \\
Marital Status & \\
Single & $97(91.5)$ \\
Married/living with partner & $9(8.5)$ \\
Schooling & \\
Grade 1-4 & $6(5.7)$ \\
Grade 5-9 9 & $83(78.3)$ \\
Grade10-12 & $16(15.1)$ \\
Higher education & $1(0.9)$ \\
School failure & $84(79.2)$ \\
Profession & $65(61.3)$ \\
Student & $18(17)$ \\
Housewife & $18(17)$ \\
Unemployed & $5(4.7)$ \\
Non-qualified job & \\
\hline & \\
\hline & \\
\hline & \\
\hline & \\
\hline
\end{tabular}

higher percentage of primary school - first to fourth grade $(20 \%)$ - compared to those with an unintended pregnancy (3\%), two thirds of whom were students Table 2.

Contraception Pre and Post Pregnancy Carried Until Delivery

Prior to pregnancy, the contraceptive method most commonly used by adolescents was the male condom (51\%) followed by oral combined contraceptives (28\%).

The use of the double method (oral combined contraceptives + male condom) was reported by $5 \%$ of the adolescents; the vaginal ring and the contraceptive implant have only 1 user. Almost 19\% did not use any contraceptive method before becoming pregnant - Table 3 .

After pregnancy there was a change in the contraceptive method in $93.4 \%$ of cases.

The contraceptive implant then became the most chosen method for $71 \%$ of adolescents, oral combined contraceptives remained as the second most used method (18\%) and the administration of medroxyprogesterone acetate was chosen in $2 \%$ of cases. We observed a more varied use of contraceptive methods, with the choice of injectable progestin, the transdermal patch and the intrauterine device

Table 2

Pregnancy Planning in Adolescents who Carried Pregnancy Until Delivery

\begin{tabular}{|c|c|c|c|}
\hline & $\begin{array}{l}\text { Intended } \\
\text { Pregnancy }\end{array}$ & $\begin{array}{l}\text { Unintended } \\
\text { Pregnancy }\end{array}$ & $P$-Value \\
\hline & $\mathrm{N}=15(14 \%)$ & $\mathrm{N}=91(86 \%)$ & \\
\hline Age $(y)$, Mean \pm SD & $16 \pm 1.22$ & $16 \pm 1.05$ & .819 \\
\hline$\leq 15 \mathrm{y}, \mathrm{n}(\%)$ & $5(33)$ & $26(29)$ & .920 \\
\hline$>15 \mathrm{y}, \mathrm{n}(\%)$ & $10(67)$ & $65(71)$ & \\
\hline Caucasian race, n (\%) & $8(53)$ & $62(68)$ & .377 \\
\hline $\begin{array}{l}\text { Married/living with a } \\
\text { partner, n (\%) }\end{array}$ & $8(53)$ & $1(1)$ & $<.001$ \\
\hline Schooling $\leq 4$ th grade, $\mathrm{n}(\%)$ & $3(20)$ & $3(3)$ & .036 \\
\hline Student, n (\%) & $4(27)$ & $61(67)$ & .004 \\
\hline
\end{tabular}

SD, Standard deviation. 
Table 3

Contraceptive Choices Pre and Post Pregnancy Carried until Delivery

\begin{tabular}{lcccr}
\hline \multicolumn{1}{c}{ Method } & Pre-pregnancy & & Post-pregnancy & P-Value \\
\cline { 2 - 2 } & $\mathrm{n}(\%)$ & & $\mathrm{n}(\%)$ & \\
\hline None & $20(19)$ & & $0(0)$ & $<.001$ \\
Male condom & $54(51)$ & & $0(0)$ & $<.001$ \\
Oral combined contraceptives & $30(28)$ & & $19(28)$ & .058 \\
Vaginal ring & $1(1)$ & & $2(2)$ & 1.000 \\
Transdermal patch & $0(0)$ & & $2(2)$ & .500 \\
LARC & $1(1)$ & & $83(78)$ & $<.001$ \\
Contraceptive implant & $1(1)$ & & $75(71)$ & $<.001$ \\
Intrauterine device & $0(0)$ & & $6(6)$ & .031 \\
Injectable progestin & $0(0)$ & & $2(2)$ & .500 \\
Total & 106 & 106 & \\
\hline
\end{tabular}

only being mentioned to after pregnancy. In no case was the use of condoms referred to.

The main differences we found are related to the absence of contraception $(P<.001)$ and the use of the male condom $(P<.001)$ before pregnancy and to the use of LARC $(P<$ $.001)$, especially the contraceptive implant and the intrauterine device after pregnancy.

Part II - Contraceptive Choices after Pregnancy Carried Until Delivery Versus Voluntary Termination of Pregnancy

Comparison of Samples

Considering Group 1 - teenagers who chose to carry their pregnancy to delivery ( $\mathrm{n}=106$, described above) and Group 2 - the same number of teenagers who opted for abortion, we found that the latter are more often Caucasians (92.5\% vs $66 \%, P<.001)$ and students (90.6\% vs $61.3 \%, P<.001)-$ Table 4.

Although in Group 2 we found a higher percentage of students, there is also a greater school failure $(89.6 \%$ vs $79.2 \%)$, with fewer adolescents with academic education beyond the ninth grade ( $4.7 \%$ versus $16 \%, P=.005)$, which would be expected in adolescents with an average age of 16 years.

Contraceptive Choices after a Pregnancy Carried Until Delivery Versus after Pregnancy Termination

The different contraceptive choices of adolescents of the 2 groups are described in Table 5.

All adolescents reported the use of a contraceptive method.

Table 4

Characterization of Adolescents of Both Groups

\begin{tabular}{|c|c|c|c|}
\hline & $\begin{array}{c}\text { Group } 1 \\
\text { Pregnancy } \\
\text { Carried Until Delivery }\end{array}$ & $\begin{array}{c}\text { Group } 2 \\
\text { Pregnancy } \\
\text { Termination }\end{array}$ & $P$-Value \\
\hline & $\mathrm{n}=106$ & $\mathrm{n}=106$ & \\
\hline Age $(y)$ & & & .847 \\
\hline Average \pm SD & $16.00 \pm 1.07$ & $16.03 \pm 1.06$ & \\
\hline Minimum - Maximum & $\begin{array}{c}13-18 \\
\text { n (\%) }\end{array}$ & $\begin{array}{c}12-17 \\
\mathrm{n}(\%)\end{array}$ & \\
\hline Caucasian race & $70(66)$ & $98(92.5)$ & $<.001$ \\
\hline Married/living with a partner & $9(8.5)$ & $3(2.8)$ & .084 \\
\hline Nulliparous & $104(98.1)$ & $100(94.3)$ & .280 \\
\hline Schooling $>$ 9th grade & $17(16)$ & $5(4.7)$ & .005 \\
\hline Student & $65(61.3)$ & $96(90.6)$ & $<.001$ \\
\hline School failure & $84(79.2)$ & 95 (89.6) & .057 \\
\hline
\end{tabular}

Table 5

Postpregnancy Contraceptive Choices

\begin{tabular}{|c|c|c|c|}
\hline Method & $\begin{array}{c}\text { Group } 1 \\
\text { Pregnancy } \\
\text { Carried Until Delivery }\end{array}$ & $\begin{array}{c}\text { Group } 2 \\
\text { Pregancy } \\
\text { Termination }\end{array}$ & $P$-Value \\
\hline & $\mathrm{n}(\%)$ & $\mathrm{n}(\%)$ & \\
\hline Oral combined contraceptives & $19(18)$ & $61(58)$ & $<.001$ \\
\hline Vaginal ring & $2(2)$ & $1(1)$ & 1.000 \\
\hline Transdermal patch & $2(2)$ & $1(1)$ & 1.000 \\
\hline LARC & $83(78)$ & $44(41)$ & $<.001$ \\
\hline Contraceptive implant & $75(71)$ & $41(39)$ & $<.001$ \\
\hline Injectable progestin & $2(2)$ & $1(1)$ & 1.000 \\
\hline Intrauterine device & $6(6)$ & $1(1)$ & .119 \\
\hline Total & 106 & 106 & \\
\hline
\end{tabular}

While in Group 1 the contraceptive implant was their main choice $(70.8 \%)$, followed by combined contraceptives (17.9\%), in Group 2 teenage girls preferred oral combined contraceptives (57.7\%), with the contraceptive implant being the second most chosen method (38.7\%). The choice for the intrauterine device occurs mainly in Group 1 (5.7\% vs $0.9 \%$ in Group 2, $P=.119$ ).

In both groups the use of the vaginal ring, the transdermal patch and the injectable progestin is mentioned by less than $2 \%$ of adolescents.

The increased use of oral combined contraceptives by Group 2 and the choice of LARC (including the contraceptive implant) especially by Group 1 are statistically significant $(P$ $<.001$ ).

However, adolescents in both groups had significantly different demographic characteristics (Table 4) so, in order to assess the real impact of pregnancy outcomes in terms of contraceptive choice- oral combined contraceptives and LARC (contraceptive implants), we performed a multivariate analysis, shown in Table 6.

The analysis of Table 6 allows us to conclude that the outcome of pregnancy is the only variable with impact on contraceptive choices $(P<.001)$.

Thus, after a delivery, adolescents prefer the use of LARC [78.4\% vs 40.5\%, OR: 5,958 - 95\% (2.914 to 12.181 ), $P<.001$ ], mainly contraceptive implants [70.8\% vs 38.7\%, OR: 4.371 - 95\% (2.224 to 8.591), $P<.001$ ], to oral combined contraceptives [17.9\% vs 57.5\%, OR: 0.118 - 95\% CI (0.054 to 0.258), $P<.001$ ] when compared to those adolescents who opt for abortion.

Table 6

Factors Influencing Postpregnancy Contraceptive Choices

\begin{tabular}{lcccc}
\hline \multicolumn{1}{c}{ Contraceptive Method } & Odds Ratio & $95 \% \mathrm{CI}$ & $P$-Value \\
\hline 1. Oral combined contraceptives & & & & \\
Pregnancy (0) versus termination (1) & 0.118 & 0.054 & 0.258 & $<.001$ \\
Caucasian race & 0.889 & 0.369 & 2.140 & .793 \\
Schooling $>$ 9th grade & 2.775 & 0.955 & 8.061 & .061 \\
Student t & 0.696 & 0.300 & 1.618 & .400 \\
2. LARC & & & & \\
Pregnancy (0) versus termination (1) & 5.958 & 2.914 & 12.181 & $<.001$ \\
Caucasian race & 0.780 & 0.339 & 1.792 & .558 \\
Schooling $>$ 9th grade & 2.463 & 0.894 & 6.783 & .081 \\
Student t & 0.859 & 0.389 & 1.792 & .708 \\
3. Contraceptive implant & & & & \\
$\quad$ Pregnancy (0) versus termination (1) & 4.371 & 2.224 & 8.591 & $<.001$ \\
Caucasian race & 0.691 & 0.317 & 1.505 & 352 \\
Schooling $>$ 9th grade & 2.164 & 0.814 & 5.753 & 122 \\
Student & 0.684 & 0.324 & 1.445 & .320 \\
\hline
\end{tabular}

CI, Confidence interval. 


\section{Discussion}

In our sample, pregnancy was mostly unplanned (85.8\%), this data being similar to international data, ${ }^{10}$ even though $81.1 \%$ of pregnant teenagers mentioned the use of at least 1 contraceptive method prior to pregnancy. This data matches those presented in the 4th National Health Survey, 2005-2006 ${ }^{11}$ and by the Portuguese Society of Gynecology, ${ }^{2}$ according to which $80.2 \%$ of adolescents between 15 and 19 years reported using contraceptive methods, also being the age group which presented the highest user rate.

Previous studies show that the high rate of teenage pregnancy seems to be associated with a high rate of incorrect use of contraceptive methods and their discontinuation. ${ }^{12}$ The latter is higher in the first 6 months of use and is mainly due to beliefs and myths related to contraception, to sporadic or short-term relationships and to the need that some teenagers feel to hide their sexual life and contraception. ${ }^{4,12}$ Teenagers are approximately twice as liable to contraceptive failure as women over 30 years of age. ${ }^{13}$ However, it should be noted that planned pregnancy in adolescence is a reality that should be taken into account - $14.2 \%$ of our cases, in ages $\geq 13$ years.

In our study, even though the majority of adolescents are students, there was a high rate of school failure. This fact is particularly prominent in cases of planned pregnancy, the group which shows the lowest percentage of students and the lowest education levels. The association between school failure, lack of interest in school or lack of academic and professional future plans and teenage pregnancy has already been studied. ${ }^{14}$

As for contraception, the main contraceptive methods used prior to a pregnancy carried until delivery were oral combined contraceptives and male condoms. These data match the findings of other authors, according to which most adolescents use contraceptive methods which are more user dependent. ${ }^{10,13}$ After delivery there was an increased use of LARC, with preference given to contraceptive implants (0 9\% vs 70.8\%, $P<.001$ ) and intrauterine devices ( $0 \%$ vs $5.7 \%, P=.031$ ). These are methods that do not require daily motivation, that have a lower failure rate, and if used for a year or longer, are more cost-effective. ${ }^{4}$

The biggest risk of a teenager mother is to get pregnant again, increasing adverse effects on mother and child. Approximately $35 \%$ of recently pregnant adolescents repeat pregnancy within 2 years. ${ }^{9}$ A pregnancy carried till delivery and consequently the existence of a child in adolescence turns out to have a strong impact in personal, family, social, and professional life. We believe that these teenagers are more motivated to the use of LARC since these methods give them the chance of delaying the second pregnancy to a later stage of their lives.

Since there are few contraindications to these methods, LARC, especially contraceptive implant and intrauterine devices, become the favorite contraceptive methods for women who wish to avoid unplanned pregnancies, regardless of how old they are. 6,10

In our sample, after pregnancy, the use of male condoms has been replaced by the use of other methods. The effectiveness of other contraceptive methods in preventing pregnancy is recognized and seen as superior to the male condom. However, adolescents being a risk group for sexually transmitted infections, it is particularly important to strengthen the continued use of barrier methods in combination with hormonal contraceptive methods.

When we compare the contraceptive options of teenagers who decided to continue with their pregnancy with those who chose to terminate it, and after adjustment, we conclude that the outcome of the pregnancy was the main factor in the choices that were made.

With a confidence interval of 95\%, the results show that teenagers who choose to continue with their pregnancy choose LARC 6 times more and the contraceptive implant 4 times more than those teenagers who choose to terminate their pregnancy. The probability of choosing oral combined contraceptives is $88 \%$ higher in the pregnancy termination group. This last result contradicts the ones found by Madden et al which concluded that women that had recently aborted use more LARC than those who hadn't. ${ }^{7}$ Nevertheless some other variables must be considered particularly the age of the included women and the number of terminations of pregnancy. Data not published but collected in our unit show that in our teenager population a meaningful increase of LARC occurs only after a relapse or termination of pregnancy. Moreau et al described that teenagers with previous delivery and preceding abortion chose LARC at a larger extent.

The fact that the contraceptive information is given by the same health professionals to all the pregnant teenagers and that all different contraceptive methods are provided reduces the bias that could be created by different counseling and method availability. Although their use has increased, the intrauterine devices are chosen by only a small percentage of pregnant teenagers. The free supply of contraceptive methods is a recognized strategy to increase the use of contraception and it has already been shown that the use of LARC, especially when started immediately after delivery or abortion is associated with a decrease in repetition of an unplanned pregnancy. And so, the supply and use of LARC should be encouraged in order to reduce the number of the unplanned pregnancies in adolescence.

The authors consider the strongest points of this study to be the use of a paired sample (where each adolescent is both the case and the control of themselves) in the evaluation of contraceptive choices before and after pregnancy, since it allows to eliminate conditioning factors that might exist if one would compare different groups of adolescents; and also, the elimination of the breastfeeding period which, in itself, was a contraindication to the use of contraceptive methods containing estrogens.

We consider the biggest limitation of this study to be the size of the samples and the retrospective data collection.

We end this study by concluding that teenage pregnancy and its analyzed outcomes are a factor of change in future contraceptive choices.

\section{Acknowledgments}

This work received the Award in Contraception - Portuguese Society of Contraception /Gedeon Richter Portugal Lda. 


\section{References}

1. Felice ME, Feinstein RA, Fisher M, et al: American Academy of Pediatrics. Committee on Adolescence. Contraception in adolescents. Pediatrics 1999; 104(5 Pt 1):1161

2. SPG: Avaliação das práticas contraceptivas das mulheres em Portugal - 2006.

3. Klein JD: American Academy of Pediatrics Committee on Adolescence: Adolescent pregnancy: current trends and issues. Pediatrics 2005; 116:281

4. Faculty of Sexual and Reproductive Healthcare Clinical Guidance: Contraceptive choices for young people. Clinical Effectiveness Unit 2010

5. Say R, Mansour D: Contraceptive choice for young people. J Fam Plann Reprod Health Care 2009; 35:81

6. American College of Obstetricians and Gynecologists Committee on Gynecologic Practice; Long-Acting Reversible Contraception Working Group: ACOG Committee Opinion no. 450: Increasing use of contraceptive implants and intrauterine devices to reduce unintended pregnancy. Obstet Gynecol 2009; 114:1434

7. Madden T, Secura GM, Allsworth JE, et al: Comparison of contraceptive method chosen by women with and without a recent history of induced abortion. Contraception 2011; 84:571
8. Moreau C, Trussell J, Bajos N: Contraceptive paths of adolescent women undergoing an abortion in France. J Adolesc Health 2012; 50:389

9. Baldwin MK, Edelman AB: The effect of long-acting reversible contraception on rapid repeat pregnancy in adolescents: a review. J Adolesc Health 2013; 52(4 Suppl):S47

10. Whitaker AK, Gilliam M: Contraceptive care for adolescents. Clin Obstet Gynecol 2008; 51:268

11. Instituto Nacional de Saúde Doutor Ricardo Jorge: Inquérito Nacional de Saúde 2005-2006.

12. Vaughan B, Trussell J, Kost K, et al: Discontinuation and resumption of contraceptive use: results from the 2002 National Survey of Family Growth. Contraception 2008; 78:271

13. Speroff L, Darney PD: A Clinical Guide for Contraception. Philadelphia Lippincott Williams Wilkins, 2011, pp 351-364

14. Bonell C, Allen E, Strange V, et al: The effect of dislike of school on risk of teenage pregnancy: testing of hypotheses using a longitudinal data from a randomised trial of sex education. J Epidemiol Community Health 2005 59:223 